\title{
The Effect of Health Educational Program for Pregnant Women about Knowledge and Use of Folic Acid Supplementation
}

\author{
Awatef Abd El Razek Mohamed ${ }^{(1)}$, Azza Mohamed Hafez, ${ }^{(2)}$, \\ Tahany Elsayed Elsayed Amr ${ }^{(3)}$ \\ ${ }^{1}$ Assistant Professor of Community Health Nursing, Faculty of Nursing, Minia University. \\ ${ }^{2}$ Assistant Professor of Maternal and Child health Nursing-Faculty of Nursing, Minia University. \\ ${ }^{3}$ Lecturer of Maternal and Newborn health Nursing, Faculty of Nursing, Menoufia University. Egypt.
}

\begin{abstract}
:
Introduction: Vitamin $B_{9}$ (folic acid and folate) is essential to numerous bodily functions. The human body needs folate to synthesize, repair, and methylate Deoxyribonucleic acid (DNA) as well as to act as a cofactor in certain biological reactions. It is especially important in aiding rapid cell division and growth, such as in infancy and pregnancy.

Aim: The aims of this study were to assess the knowledge and effect of the educational program regarding folic acid supplementation among pregnant women.

Method: Pre-Posttest design was utilized in this study.

Setting: this study was conducted at the Child Health (MCH) centers at Minia City.

Sample: 100 pregnant women who are randomly selected were included in this study.

Tool: A Structured interview questionnaire was used in this study which included personal data socioeconomic data and knowledge related to folic acid.

Results: $75 \%$ of studied sample not taken folic acid during the pregnancy period.Also the results show that there were high differences between pre and post educational program among them as regard mean of total knowledge scores.

Conclusion: There were poor knowledge about folic acid among pregnant women and increase mean total knowledge scores after the educational program. So, we recommend that, development of health education program is essential for pregnant women regarding folic acid usage.
\end{abstract}

Keywords: Educational program, Folic Acid, Knowledge, Pregnant women

\section{Introduction}

Folic acid (FA) is a vitamin found in certain foods, including dark green leafy vegetables, peanuts and oranges (Safi and Chalouhi 2012). Folic acid is the fully oxidized monoglutamy form of the water-soluble vitamin commercially used and fortified foods. In terms of metabolism, folic acid is converted into coenzyme forms required in numerous one-carbon transfer reactions involved in the synthesis, inter-conversion and modification of nucleotides, amino acids, and other essential structural and regulatory compounds. Interference with Deoxyribonucleic acid (DNA) synthesis, reduced cell growth and destruction of cell division are possible effects of an absence of folic acid. Folic acid supplementation before and during early pregnancy can reduce the prevalence of neural tube defect (NTD) (Simone et al., 2006).

Folic acid was known under different names from 1933 by its curative effects in deficiency states in human and animals and it is essential for the maturation of red blood cell foods such as liver, meat, dairy products, eggs, milk, fruits and cereals are good dietary source as leafy vegetables. "Women of child-bearing age, are recommended to consume $0,4 \mathrm{mg} / \mathrm{day}$ of FA, to reduce the risk of congenital defects. The intake of folic acid should start at least one month before the conception and should continue for the first quarter of pregnancy" (American College of Medical Genetics Foundation 2004 \& Salermo et al.,2013).

Deficiency of folic acid has been associated with anemia and other adverse outcomes in pregnancy such as neural tube defects (NTD). The recommendations for prevention of outcomes are difficult to achieve through diet only, and folic acid supplement and food fortification are feasible public health strategies. It is necessary to determine the usual diet and supplement use among women of reproductive age, including an accurate assessment of other dietary micronutrients (Almeida and Cardoso 2010).

Congenital abnormalities (CAs) concern all diseases of organs or body parts developed in utero. They can be either isolated localized in one organ or multiple affecting at least two organs grouped into a syndrome, a sequence, or an association. Their prevalence is about $14 \%$ of all human fetuses considering all types of abnormalities (Bethany et al., 2012 ). Among major CAs, are congenital heart diseases account for $25 \%$, limb defects for $20 \%$, and nervous system abnormalities for $10 \%$ (Simone et al., 2006). Moreover, CAs represent the 
first cause of infant mortalities, with an increasing proportion (more than 25\%) in both developed and developing countries (Safi and Chalouhi 2012). Prevention of CAs is defined by individual and public health strategies that can reduce their prevalence.

These active strategies include nutritional interventions, prevention of maternal infections and diseases, peri-conceptional care of sick mothers (epileptic or diabetic), control of professional and environmental exposure to teratogens, and special attention to pregnancies exposed to major health determinants such as obesity, tobacco, alcohol, and drugs (Safi and Chalouhi 2012). Congenital anomalies play a significant role in perinatal and neonatal morbidity and mortality. The frequency of these congenital anomalies varies in different populations. As many infectious diseases have been controlled by use of vaccines and antibiotics (Nadia et al.,2007).

It is difficult and costly to treatment and rehabilitate the morbidity children ((Simone et al., 2006).\& Salermo et al., 2013). Finding the variation in the frequency of congenital anomalies may be helpful for us in planning healthcare measures for possible prevention of such anomalies. The major causes of perinatal and neonatal death, both in developed and developing countries are congenital anomalies. They are presumed to be more prevalent in populations with cousin marriages. Congenital anomalies are either single isolated defects or present as multi - pleanoma lies in a single individual. A syndrome is defined as a pattern of multiple abnormalities that are related by path physiology and result from common, defined etiology (Gillani et al., 2011).

Congenital anomalies are a major cause of admission and prolonged stay in nursery; they are also an important cause of early and late neonatal deaths. The causes for these anomalies are multimactorial (Gillani et al., 2011).

\section{Significance Of The Problem}

There was lack of knowledge among families and the health authorities about the importance of genetic counseling in the prevention of congenital malformations. Primary or true prevention is at present limited, for example folic acid can prevent only a small proportion of congenital anomalies (Safi and Chalouhi 2012). Tertiary prevention (corrective surgery or medical treatment of anomalies) is successful and curative for some malformations (Malak and Al-Hakeem 2012). The pattern and prevalence of congenital anomalies may vary over time or geographical location, thereby reflecting a complex interaction of known and unknown genetic and environmental factors including sociocultural, racial and ethnic variables (American College of Medical Genetics Foundation 2004 Nadia et al., 2007).

\section{Aim Of The Study}

1. Assess the knowledge regarding folic acid supplementation among pregnant women.

2. Assess the effect of applying educational program on pregnant women knowledge and use of folic acid supplementation

\section{Methodology}

This pretest-posttest study measured changes in pregnant women knowledge and use of folic acid. Pregnant women who were admitted to Maternal and Child Health $(\mathrm{MCH})$ centers at Minia city were the study sample. The number of women who were found eligible for participation was 100 pregnant women who are agree to participate in the study. The study assessed women's knowledge and use of folic acid as follows: before and post the intervention The time interval between the pre-test and the post-test was (12) weeks; a period long enough to minimize the effect of the pre-test on the results and conclusions of the experiment.. Data was collected within 12 months from January to December 2015, two days/week at official time from 8 am: $12 \mathrm{pm}$. The researchers met the subjects at MCH centers.

Ethical approval was obtained from the responsible authorities of. MCH centers. Participants' consent was obtained early of the study and steps to ensure confidentiality and anonymity were attained. A pilot study to assess the clarity of the study tools was carried out on ten women.

\section{Instruments}

An interview questionnaire which included personal socioeconomic questions as age, educational level, trimester and socio- economic level also questions about the knowledge related to definition of folic acid, resources, harmful effect of its lack, amount and requirement of folic acid, importance of its, and source of knowledge. The scoring system was designed 20 questions, every question equal two scores and total scores equal 30 scores. After the calculation of each subject's scores the subject who was has: less than 50\% (less than 20 scores) have poor knowledge, 50-70\% (20 - less than 28 scores) have satisfactory knowledge and more than $70 \%$ (28 scores) have good knowledge. 


\section{Reliability of the instrument}

To ensure the test reliability, the researcher followed test/retest technique. The researcher applied it to a pilot sample of (10) women who were excluded from the study with a two-week period between the test and the re-test. The reliability of the test was calculated using correlation coefficient and it was 0.89 which is appropriate for conducting such a study.

\section{Validity of the instrument}

The researcher validated the instrument by submitting it to a jury of three supervisors of maternity nursing and medical at Minia University. The researcher followed the recommendations of the referees and made amendments accordingly.

\section{Folic acid education program}

This three hours interactive learning session was delivered to those women admitted to MCH centers. The program consisted of a formal lecture and discussion bout folic acid knowledge and how to uses.

\section{Results}

Table: (1). Shows that a total of 100 pregnant women participated in this study, their mean age (Standard Deviation) were $23.0 \pm 4.08$ years old. Around one third of study sample were primary education, at third trimester and middle socioeconomic status. This table also shows that the majority of subject not taking a folic acid during pregnancy period and this considered as a serous indicators.

Table (2) demonstrates the knowledge about folic acid among studied sample; as regards to concept of folic acid; fourthy fifth percent of the studied sample told that is vitamin. $(21 \%)$ of the studied sample don't know the source of folic acid. About two third (63\%) of them don't know harmful effect of its deficiency. More than two third $(70 \%)$ of the sample don't know how to avoid the defiency of folic acid. In relation to how to avoid side effect of folic acid defiency; two third of the sample don't know. As regards to the quantaty of folic acid, about two third (63.5\%) of the sample don't know the proper amount. In relation to knowledge about the importance of folic acid near to three quarter (73.5\%) of the studied sample don't know the importance of folic acid. The most $(82 \%)$ of them need health education. the most percentage of sources of knowledge about folic acid from health care provider were doctors and nurses $(78.0 \%)$.

Table (3). Shows the distribution knowledge level in pre\& post educational program among studied sample. it was observed that there an improvement in women level of knowledge regarding folic acid post program .

Table (4). Demonstrate the relation between level of knowledge regarding folic acid post program and level of education among studied sample with statistical significant

Table 1: Demographic characteristics of the studied sample

\begin{tabular}{|l|l|l|}
\hline \multicolumn{1}{|c|}{ Variable } & No & $\%$ \\
\hline Mean age (years ) & \multicolumn{2}{|c|}{$23.04 \pm 4.08$ years } \\
Mean + SD & \multicolumn{2}{|c|}{} \\
\hline Level of education & 37 & 37 \\
Primary & 29 & 29 \\
Secondary & 34 & 34 \\
High education & & \\
\hline Trimester & 20 & 20 \\
$1^{\text {st }}$ & 30 & 30 \\
$2^{\text {nd }}$ & 50 & 50 \\
$3^{\text {rd }}$ & & \\
\hline Folic acid taken Intake & 25 & 25 \\
Yes & 75 & 75 \\
No & & \\
\hline Socio-economic level & 3 & 3 \\
Low & 61 & 61 \\
Middle & 36 & 36 \\
High & \multicolumn{2}{|l|}{} \\
\hline
\end{tabular}

Table 2: Distribution the knowledge about folic acid among studied sample

\begin{tabular}{|l|l|l|}
\hline Variables & No & $\%$ \\
\hline Concept of folic acid & & \\
- $\quad$ Vitamin & 45 & 45 \\
- $\quad$ Type of mineral $\quad 34$ & 34 \\
- Don't know $\quad 21$ & 21 \\
\hline Sources of FA $\quad$ know & 25 & \\
- $\quad 75$ & 25 \\
& & 75 \\
\hline
\end{tabular}




\begin{tabular}{|c|c|c|}
\hline Don't know & & \\
\hline $\begin{array}{l}\text { Know harmful effect of its deficiency } \\
\text { - } \\
\bullet\end{array}$ & $\begin{array}{l}37 \\
63\end{array}$ & $\begin{array}{l}37 \\
63\end{array}$ \\
\hline $\begin{array}{ll}\text { Required quantity } \\
- & 400 \text { micro/day } \\
\text { - } & 400 \text { milligram / day } \\
\text { - } & \text { Don't know }\end{array}$ & $\begin{array}{l}20 \\
16 \\
64\end{array}$ & $\begin{array}{l}20 \\
16 \\
64\end{array}$ \\
\hline $\begin{array}{l}\text { Know importance of folic acid } \\
\qquad \quad \text { Yes } \\
\qquad \quad \text { No }\end{array}$ & $\begin{array}{l}26 \\
74\end{array}$ & $\begin{array}{l}26 \\
74\end{array}$ \\
\hline $\begin{array}{l}\text { Avoid deficiency of FA } \\
\bullet \quad \text { Know } \\
\bullet \quad \text { Don't know } \\
\end{array}$ & $\begin{array}{l}30 \\
70 \\
\end{array}$ & $\begin{array}{l}30 \\
70 \\
\end{array}$ \\
\hline $\begin{array}{l}\text { Take folic during pregnancy } \\
-\quad \text { Yes } \\
\bullet \quad\end{array}$ & $\begin{array}{l}60 \\
40\end{array}$ & $\begin{array}{l}60 \\
40\end{array}$ \\
\hline $\begin{array}{l}\text { You need health education } \\
\text { - } \\
\bullet\end{array}$ & $\begin{array}{l}82 \\
18\end{array}$ & $\begin{array}{l}82 \\
18\end{array}$ \\
\hline $\begin{array}{l}\text { Source of knowledge } \\
\text { - } \\
\text { - } \\
\text { Doctor or Nurse } \\
\text { - } \\
\text { Internet } \\
\text { T.V/media } \\
\text { brochure }\end{array}$ & $\begin{array}{l}78 \\
8 \\
6 \\
8\end{array}$ & $\begin{array}{l}78 \\
8 \\
6 \\
8\end{array}$ \\
\hline
\end{tabular}

Table 3: Distribution knowledge level in pre\& post educational program among studied sample

\begin{tabular}{|l|l|l|l|l|}
\hline Item & Pre Program No. & $\mathbf{\%}$ & Post Program No. & \% \\
\hline Good & 18 & 18 & 56 & 56 \\
\hline Satisfactory & 19 & 19 & 22 & 22 \\
\hline poor & 63 & 63 & 22 & 22 \\
\hline
\end{tabular}

Table 4: Relation between level of knowledge regarding folic acid post program and level of education among studied sample

\begin{tabular}{|l|l|l|l|l|}
\hline \multirow{2}{*}{ Level of Knowledge } & \multicolumn{2}{|l|}{ Level of education } & P-Value \\
\cline { 2 - 5 } & primary & secondary & High education & \\
\hline Good & 9 & 15 & 32 & 0.001 \\
\hline Satisfactory & 10 & 11 & 1 & 0.001 \\
\hline Poor & 18 & 3 & 1 & 0.003 \\
\hline
\end{tabular}

\section{Discussion}

This pre-posttest study was aimed to assess the knowledge regarding folic acid supplementation among pregnant women in Minia city and assess the effect of the educational program on their knowledge and uses of folic acid. Their mean age (Standard Deviation) were $23.0 \pm 4.08$ years old as shown in table1. Two third (68\%) of them was high socio-economic level .

About two third of the studied sample know little knowledge about the folic acid and the most of them need health education. so it is important to implement educational intervention .This agree with study conducted by bagheri, behnampour, and ghaemi (2010) who stated that, there is a strong need for immediate public health education initiative. Information to specifically inform women about the need to take folic acid for the prevention of NTDs by all tiers of healthcare system and media, can improve the intake of folic acid during the protective period.

Participant in this study reported that, the health care providers were the main source of knowledge about folic acid. This agree with study conducted by Murad, (2013) who mentioned that, main source of knowledge about folic acid among the women was through the health workers (Al-Holy 2013).

About two third of pregnant women in this study don't know harmful effect of folic acid deficiency, because there is no educational intervention about folic acid supplementation before; this agree with studies conducted (National Institute of Population Studies 2007, Wade and McBeth 2012) stated that, no studied of educational intervention on folic acid topic delivered to the females in college for women.

In relation to knowledge about the importance of folic acid; in near to three quarter of the studied sample don't know the importance of folic acid. This agree with (Jamela et al.,2008) who stated in her study that, a high percentage of educated women were not aware by the importance of folic acid.

The study has highlighted a good level of knowledge among highly educated women whereas those women who were exposed health education about folic acid with positive correlation was observed $(\mathrm{P}<.001)$. On the contrary study carried out in Malaysia showed that education was positively associated with vitamin/mineral 
supplementation (Pon et al., 2006). A study conducted by (Mohamed et al., 2012 ) the knowledge of iron rich foods was poor. Higher level of knowledge was observed in subjects with higher educational background $(\mathrm{p}<$ .001). Another study carried out in India by (Kuar and Singh) to see the effect of education on knowledge, attitude and practice of pregnant women showed that $93 \%$ of the educated women were in favor of including iron rich foods in their diet as compared to $67 \%$ in the group with no education $(\mathrm{p}<0.001)$.

These results indicate that, immediate health program consisting oral presentation and handout about folic acid is effective in increasing knowledge about uses of folic acid and importance of folic acid to prevent congenital anomalies and other complication of its deficiency.

\section{Conclusion}

According to the results of this study there was poor knowledge about folic acid among pregnant women and increase mean total knowledge scores after the educational program. So, there is need to increase the knowledge of females about the using and importance of folic acid in all setting of the community especially $\mathrm{MCH}$ centers.

\section{Recommendations}

1. Development of health education program is essential for pregnant women regarding folic acid usage.

2. Repeated the educational program after $3 \& 6$ months to evaluate the retained knowledge regarding folic acid supplementation.

\section{References}

[1]. Weinstein SJ, Hartman TJ, Stolzenberg-Solomon R, Pietinen P, Barrett MJ, Taylor PR, et al. Null association between prostate cancer and serum folate, vitamin B(6), vitamin B(12), and homocysteine. Cancer Epidemiol Biomarkers Prev. 2003;12(11 (pt 1)):1271-1272. [PubMed]

[2]. Bethany L. Murphy, Natalie A and Dipietro., Impact of a pharmacist- directed educational program on the long-term knowledge and use of folic acid among college women: a 12-month follow-up study, 2012

[3]. Simone P., Hoyer- Schushke J, Seelig M., and Steinbicker V. Knowledge among young people about folic acid and its importance during pregnancy: a survey in the Fedral State of Sexony-Anhalt 9 Germany, 2006.

[4]. Salermo B., Bianchi F, Pierini A, Baldi F, Carbone P, Mantovani A, and Taruscio D (2013). Folic acid and congenital malformation: scientific evidence and public health strategies].

[5]. Almeida, L and Cardoso, M. Recommendations for folate intake in women: implications for public health strategies. Cad. Saúde Pública vol.26 no.11 Rio de Janeiro Nov. 2010 http://dx.doi.org/10.1590/S0102-311X2010001100003.

[6]. Safi, L. Joyeux, and Chalouhi, G. Periconceptional Folate Deficiency and Implications in Neural Tube Defects. ournal of Pregnancy.Volume 2012 (2012), Article ID 295083, 9 pages; http://dx.doi.org/10.1155/2012/295083.Review Article.

[7]. Malak M., and Al-Hakeem. Impact of education on knowledge and use of folic acid among Saudi women. Pak J Med Sci 2012;28(4):686-690; Impact of education on knowledge and use of folic acid among Saudi women.

[8]. Gillani S, Kazmi N, Najeeb S. Hussain S., Raza A., Pakistan ; frequencies of congenital anomalies among newborn admitted in nursery of ayub teaching hospital abbo ttabad, Pakistan ; jayub med collabbottabad 2011;23(1).

[9]. Nadia M. Fida, Jumana Al-Aama, Wafaa Nichols, Mohamed Alqahtani, (2007). A prospective study of congenital malformations among live born neonates at University Hospital in Western Saudi Arabia. Saudi Med J 2007; Vol. 28 (9)

[10]. American College of MedicalGenetics Foundation :Evaluation of the Newborn with Single or Multiple CongenitalAnomalies: A Clinical Guideline.. Accessed on 7 August 2004. Available from URL:

http://www.health.state.ny.us/nysdoh/dpprd/main.htm\#fulldoc

[11]. Clement. Basic concepts of Community Health Nursing, $2^{\text {nd }}$ edition; jaypee brothers medical publisher(p) 1td; 2011; new Delhi ( USA).p(72).

[12]. Bagheri H, Behnampour N, Ghaemi E. The frequency of Anti-Cytotoxin associated Gene A (CagA) antibody in Golestan province of Iran. J Gorgan Univ Med Sci 2010; 12: 74-8.

[13]. Al-Holy M.,A.Eidh,S.Epuru,D.Abu.Jamous and I. Ashnakty," Awareness of folic acid intake among women in the child bearing Age in hall region-Saudi arabia,"Food and nutrition Science,Vol.4 No.1,2013,pp.49-55

[14]. Wade GH,Herrman J, McBeth-Snyder L.A preconception care program for women in coolege setting.MCN Am J Matern Child Nurs.2012;37:164-170.[pub Med].

[15]. National Institute of Population Studies, Pakistan \& Macro International, USA. Pakistan Demographic and Health Survey 2006-07 Islamabad, Pakistan 2007.

[16]. Jamela A. Kari,MD. Ekhlas, S. Bardisi, Medical Students, Rabaa, M. Baitalmal, Med. Students, Ghofran A. Ageely, (2008); Folic acid awareness among female college students.

[17]. Pon LW, Noor-Aini MY, Ong FB, Adeeb N, Seri SS, Shamsuddin K,Mohamed AL, Hapizah N, Mokhtar A, Wan HW..Diet, nutritional knowledge and health status of urban middle-aged Malaysian women. Asia Pac J Clin Nutr. 2006;15(3):388-99.

[18]. Kuar M, Singh K. Effect of health education on K.A.P about anemia among in rural women of Chandigarh. Indian Journal of Community Med ,2001; 26: 22-24

[19]. Ayesha Mohannad, Farwa Rizvi, Ghazia Irfan: Impact of Maternal Education, and Socioeconomic Status on Maternal Nutritional Knowledge and Practices Regarding Iron Rich Foods and Iron Supplements, Ann. Pak. Inst. Med. Sci. 2012; 8(2): 101-105 